\title{
The Role of Carbonaceous Fragments on the Functionalization and Electrochemistry of Carbon Materials
}

Rui Gusmão, ${ }^{[a, b]}$ Eunice Cunha, ${ }^{[a]}$ Conceição Paiva,${ }^{[a]}$ Dulce Geraldo, ${ }^{[b]}$ Fernanda Proença, ${ }^{[b]}$ Fátima Bento ${ }^{[b]}$ [a] Dr. R. Gusmão, Eunice Cunha, Dr M.C. Paiva

Instituto de Polímeros e Compósitos/I3N, Universidade do Minho, Campus de Azurem, 4800-058 Guimarães (Portugal)

[b] Dr. M. D. Geraldo, Dr. M. F. Bento, Prof. M. F. Proença

Centro de Química, Universidade do Minho, Campus de Gualtar, 4710-057 Braga (Portugal)

\begin{abstract}
Carbonaceous fragments (CF) formed by acid treatment of carbon materials have important properties that are not completely understood. In this work, CF were produced by oxidation of CNT using mineral acid followed by treatment with $\mathrm{NaOH}$. The role of CF on CNT voltammetric properties was studied using different materials: oxidized CNT (a-CNT), a-CNT refluxed in $\mathrm{NaOH}$ and neutralized with $\mathrm{HCl}(\mathrm{b}-\mathrm{CNT}$ ), pristine CNT exposed to a CF suspension (c-CNT), and b-CNT exposed to a CF suspension ( $r-C N T)$. The extension of functionalization of these materials was evaluated by TGA. The spectroscopic characterization (UV/Vis, fluorescence, FTIR, Raman and NMR) of CF indicates the presence of graphene-type conjugated aromatic rings with highly oxidized moieties.

In this work we demonstrate that CF are responsible for the ameliorated voltammetric properties of oxidized CNT. Adsorption of CF on oxidized and non-oxidized CNT showed that CF provide active sites for hydroquinone (HQ) adsorption, enhancing current responses. The interaction of CF with carbon materials depended on both the surface oxidation degree and the surface roughness. Voltammograms from CF adsorbed on oxidized CNT indicate the presence of labile supramolecular structures with a voltammetric response typical of quinoid units. Carbon materials functionalized with CF displayed lower peak potentials and higher currents (30 to $180 \%$ ) than the un-modified electrodes demonstrating that CF is a promising material for sensors design.
\end{abstract}

\section{Introduction}

Recurrent use of carbon nanoparticles (CNP) in sensors design is due to their unique features that change dramatically the interface properties of electrodes. ${ }^{[1,2]}$ Improvement of heterogeneous charge transfer rates and increased ability to immobilize molecules may justify the ameliorated sensitivity and detection limits achieved with CNP modified electrodes. ${ }^{[3,4]}$ The high surface area, ${ }^{[5]}$ the increased amount of edges-plane sites $^{[6]}$ and the presence of catalytic impurities are often indicated as key features for CNP electrochemical properties. The effect of impurities, either metallic, ${ }^{[7]}$ graphitic $^{[8-14]}$ or of residual surfactants ${ }^{[15]}$ has been studied on the catalytic and redox properties of CNP.

Purification of CNP may be extremely challenging since the impurities, particularly graphitic, display similar chemical properties. Oxidation by strong oxidizing agents under reflux, ${ }^{[16-18]}$ electrochemical oxidation $^{[19-21]}$ or by heat ${ }^{[22]}$ are alternative treatments for CNP. The introduction of oxygen groups in the graphitic impurities improves their solubility in polar solvents and allows their removal from the CNP surface. These oxidative treatments have drawbacks, namely their limited efficiency on removing impurities, ${ }^{[23]}$ the production of structural defects and the extensive functionalization of CNP. ${ }^{[20,24,25]}$ Graphene oxide (GO) ${ }^{[26]}$ 
and highly oxidized carbonaceous fragments (CF), also denominated as carbonaceous debris (OD), ${ }^{[27]}$ are important products that result from oxidative treatments of CNP. ${ }^{[17,18]}$ Regardless of the starting carbon material undergoing oxidation, CF are generally described as highly oxidized polyaromatic fragments strongly adsorbed on the carbon matrix by $\pi-\pi$ stacking, hydrogen bonding, and van der Waals interactions. ${ }^{[28]}$ These nanostructures may be extracted from the precursor materials by reflux in $\mathrm{NaOH}$ solution. ${ }^{[29-32]}$

Several authors studied the effect of CF on the electrochemical performance of CNT and graphene materials. ${ }^{[32-39]}$ The presence of CF was reported to have a positive effect on the electrochemical oxidation of $\beta$-nicotinamide adenine dinucleotide (NADH) and ascorbic acid (AA) at glassy carbon electrode coated

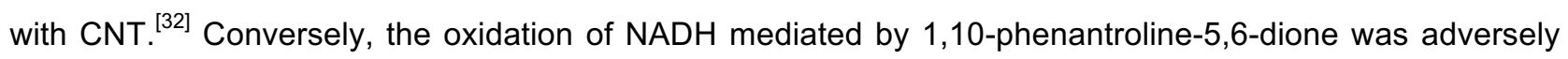
influenced by the presence of CF on the GO surface. ${ }^{[33]}$ The presence of CF on the surface of GO limits the oxidation of dopamine (DA), ${ }^{[30]}$ while on the surface of reduced graphene (RG) CF favors the oxidation of $\mathrm{DA},{ }^{[34]} \mathrm{AA}, \mathrm{NADH}$, aminophenol and $\mathrm{H}_{2} \mathrm{O}_{2} \cdot{ }^{[35]}$ Besides faradaic processes, the capacitive performance of carbon materials can be highly influenced by the presence of CF on their surface. ${ }^{[36,37]}$ The removal of CF produced a significant decrease of the capacitance of graphene, while their re-adsorption produced a capacitance recovery. A possible explanation for the improved conductivity of graphene samples containing $\mathrm{CF}$ is the increased wettability of the material. As a consequence the restacking of graphene sheets may be hindered, increasing the exposed surface area. ${ }^{[36]}$

The chemical nature of the $\mathrm{CF}$ is not entirely known. More than one hundred compounds were detected by ESI FT-ICR MS in CNT oxidation debris. ${ }^{[40]}$ Several methods were applied to characterize this material in terms of structure and electrochemical performance. Thermogravimetric analysis (TGA), reported their decomposition to take place above $200{ }^{\circ} \mathrm{C} .{ }^{[33]}$ Scanning transmission X-ray microscopy-related techniques were applied to characterize oxidized CF on CNT, demonstrating the presence of a heavily oxidized CF coating ${ }^{[41]} \mathrm{A}$ structure consisting of "three or more fused benzene rings with extended oxygen containing functional groups" was suggested by the fluorescence spectrum, ${ }^{[32]}$ and supported by Fourier Transform Infrared Spectroscopy (FTIR) and X-ray photoelectron spectroscopy (XPS) analysis. ${ }^{[32,35]}$

In the present work, the CF produced by treatment of the CNT with concentrated $\mathrm{HNO}_{3}$ were characterized by thermal analysis (TGA) and spectroscopic techniques (UV/Vis, fluorescence, FTIR, Raman, NMR and EDS). These CF were used to modify electrodes of different carbon materials. Hydroquinone $(H Q)$ was used a molecular probe for the detection of carbonyl and hydroxyl groups at the surface of CNT modified electrode $^{[22]}$ and as a model polyphenol. Polyphenols have natural occurrence and can exhibit cytotoxic activity $^{[42]}$ or act as antioxidants. ${ }^{[43]}$ Besides, synthetic polyphenols used as textile dyes are frequently discarded as residues. ${ }^{[4]}$ The development of sensors for this class of compounds is therefore of great importance to health, food and environmental applications.

\section{Experimental Part}

\section{Materials}

Multiwall carbon nanotubes (CNT, NC7000, purity > $90 \%$, average length of $1.5 \mu \mathrm{m}$, average diameter of $9.5 \mathrm{~nm}$ ) were purchased from Nanocyl, S.A. (Belgium) and employed throughout. Pyrograph $®$ III carbon 
nanofibers (CNF, PR-24-PS, hollow fibers with wide diameter range from 60 to $150 \mathrm{~nm}$, maximum length $100 \mu \mathrm{m}$ ) were acquired from Applied Sciences, Inc. (USA). Graphite powder $\left(\mathrm{G}_{1 \mu \mathrm{m}}, 1-2 \mu \mathrm{m}\right)$ was purchased from Aldrich. Hydroquinone ( $\mathrm{HQ}$, Riedel-de Haen) and all other chemicals were of analytical grade or higher and were used as received. Milli-Q water was used in the preparation of solutions.

\section{Instrumentation}

Infrared spectra of CF were recorded on an ABB FTIR-FTLA2000 analyzer within the range of $500-4000$ $\mathrm{cm}^{-1}$ using $\mathrm{KBr}$ pellets (about $2 \mathrm{mg}$ of material in $98 \mathrm{mg}$ of $\mathrm{KBr}$ ). The UV/Vis spectra of $\mathrm{CF}$ aqueous suspensions were recorded on a Shimadzu UV-2501 model. The absorption measurements were carried out in a quartz cell with a path length of $1 \mathrm{~cm}$. Fluorescence spectra of CF suspensions were obtained at room temperature on a FluoroMax-4 spectrophotometer (Horiba) using a quartz cell with a path length of 1 $\mathrm{cm}$ and a slit width of $5 \mathrm{~nm}$. The excitation wavelength was set at the maximum peak wavelength $(290 \mathrm{~nm})$ of the absorption spectra of CF suspension obtained from CNT oxidized during $6 \mathrm{~h}\left(\mathrm{CF}_{6 \mathrm{~h}}\right)$.

Raman spectra were acquired on a Horiba LabRam HR Evolution confocal microscope using a $532 \mathrm{~nm}$ $(2.33 \mathrm{eV})$ excitation laser. A $100 \mathrm{x}$ objective lens was used to focus the laser light on the sample. The samples were prepared by spraying the CF suspension onto a glass slide and drying.

The NMR spectra were recorded on a Bruker Avance 3400 at $400 \mathrm{MHz}$ for ${ }^{1} \mathrm{H}$ and $100 \mathrm{MHz}$ for ${ }^{13} \mathrm{C}$, including DEPT 135. Deuterated water was used as solvent. The chemical shifts are expressed in $\delta$ (ppm).

A Modulated Thermogravimetric Analyzer Q500 (TA Instruments) was used in dynamic mode for the CNT characterization. The samples were heated from room temperature to $800{ }^{\circ} \mathrm{C}$ at $10{ }^{\circ} \mathrm{C} \mathrm{min}{ }^{-1}$ under a constant nitrogen flow of $60 \mathrm{~mL} \mathrm{~min}^{-1}$.

Scanning transmission electron microscopy (STEM) was performed using a FEI Quanta 400 FEG ESEM equipped with EDAX Genesis X4M.

An Autolab PGSTAT30 potentiostat / galvanostat (Eco Chemie, The Netherlands) controlled by GPES 4.9 software was used in voltammetric experiments. A three-electrode configuration cell $(\mathrm{v}=10 \mathrm{~mL})$ was used at room temperature. A glassy carbon electrode (GCE, $r=1.5 \mathrm{~mm}, \mathrm{CHI104}, \mathrm{CH}$ Instruments, Inc.) was used as working electrode, a platinum wire as auxiliary electrode and an $\mathrm{Ag} / \mathrm{AgCl}(3.0 \mathrm{M} \mathrm{KCl}, \mathrm{CH} 1111, \mathrm{CH}$ Instruments, Inc.) as a reference electrode. Commercially available screen printed carbon electrodes (SPCE, DRP-110, carbon disk working electrode $r=2 \mathrm{~mm}$, silver pseudo-reference electrode and carbon secondary electrode) were acquired from DropSens. Voltammetric measurements using SPCE were performed covering the three electrodes with a $50 \mu \mathrm{L}$ drop of solution. Cyclic voltammograms were recorded at $100 \mathrm{mV} \mathrm{s}^{-1}$.

\section{Procedures}

The CNT were subjected to the treatments illustrated in Figure 1. The as-received CNT (CNT prist, $800 \mathrm{mg}$ ) were refluxed in concentrated $\mathrm{HNO}_{3}(100 \mathrm{~mL})$ at $100-110^{\circ} \mathrm{C}$ for 1,3 and 6 hours. After cooling to room temperature, the CNT were centrifuged, filtered and rinsed with Milli-Q water until the filtrate showed no evidence for the presence of acid, by pH measurements. The acid-treated CNT (a-CNT) were dried in a vacuum oven (Büchi glass oven B-580) overnight at $80^{\circ} \mathrm{C}$. Subsequently, a sample of $130 \mathrm{mg}$ of a-CNT were refluxed in $0.1 \mathrm{M} \mathrm{NaOH}(100 \mathrm{~mL})$ for 1 hour. After the mixture was cooled to room temperature, the 
brownish supernatant $\left(\mathrm{CF}_{0 \mathrm{~h}}, \mathrm{CF}_{1 \mathrm{~h}}, \mathrm{CF}_{3 \mathrm{~h}}\right.$ or $\mathrm{CF}_{6 \mathrm{~h}}$ depending on the $\mathrm{HNO}_{3}$ refluxing time) was separated from the black precipitate. The $\mathrm{pH}$ of the brownish supernatant containing $\mathrm{CF}_{6 \mathrm{~h}}$ was adjusted to 7 with $0.1 \mathrm{M} \mathrm{HCl}$. The precipitate obtained from $6 \mathrm{~h}$ of $\mathrm{HNO}_{3}$ reflux and $1 \mathrm{~h}$ of $\mathrm{NaOH}$ reflux (b-CNT) was re-suspended in water, neutralized with $0.1 \mathrm{M} \mathrm{HCl}$, rinsed thoroughly with Milli-Q water and then dried overnight at $80{ }^{\circ} \mathrm{C}$ under vacuum. A sample of $50 \mathrm{mg}$ of b-CNT was added to $50 \mathrm{~mL}$ of $\mathrm{CF}_{6 \mathrm{~h}}$ suspension and stirred for 1 hour, then filtered and rinsed with Milli-Q water. The solid ( $r-C N T)$ was then dried under vacuum. This procedure was repeated with $\mathrm{CNT}_{\text {prist }}$ to prepare the c-CNT Suspensions of different CNT materials (a-CNT, b-CNT, cCNT and r-CNT) were prepared in ethanol: water (1:1) at concentrations ranging from 1.01 to $1.08 \mathrm{mg} \mathrm{mL}^{-1}$. $\mathrm{CNT}_{\text {prist }}$ suspensions $\left(1.02 \mathrm{mg} \mathrm{mL}^{-1}\right)$ were prepared in $\mathrm{n}$-hexane. Suspensions were initially sonicated for 5 $\mathrm{min}$ in an ice bath and for 30 seconds prior to use. The different suspensions drop casted on the GCE surface, were allowed to dry under a lamp. Prior to modification the GCE surface was polished with alumina $(0.3$ and $0.05 \mu \mathrm{m})$ on a polishing pad, abundantly rinsed with deionized water and dried. A fixed amount of each CNT material $(4 \mu \mathrm{g})$ was deposited onto the GCE surface by drop casting ca. $4 \mu \mathrm{L}$ of the corresponding CNT suspension to prepare CNT prist@GCE, a-CNT@GCE, b-CNT@GCE c-CNT@GCE and r-CNT@GCE.

GCE modified electrodes CNF@GCE and $\mathrm{G}_{1 \mu \mathrm{m}} @ G C E$, containing $8 \mu \mathrm{g}$ of $\mathrm{CNF}$ or of $\mathrm{G}_{1 \mu \mathrm{m}}$, were prepared by drop casting ca. $8 \mu \mathrm{L}$ of each suspension onto the electrode surface. The suspensions of CNF (1.31 mg $\left.\mathrm{mL}^{-1}\right)$ and $\mathrm{G}_{1 \mu \mathrm{m}}\left(1.46 \mathrm{mg} \mathrm{mL}^{-1}\right)$ were prepared in methanol: water (1:1). These electrodes were further modified by drop casting $10 \mu \mathrm{L}$ of the $\mathrm{CF}_{6 \mathrm{~h}}$ suspension (ca. $0.8 \mathrm{mg} \mathrm{L}^{-1}$, evaluated by TGA data, see Results and discussion section) on the surface of: SPCE (CF@SPCE); GCE (CF@GCE); G ${ }_{1 \mu m}$-GCE (CF-

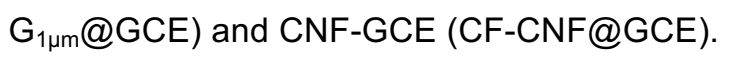

Blank solution was prepared by mixing ca. $13 \mathrm{~g}$ of potassium phosphate monobasic with $10 \mathrm{~g}$ of potassium phosphate dibasic and $\mathrm{pH}$ adjusted to 7.2 with potassium hydroxide (PB, $0.15 \mathrm{M}$ ). Milli-Q water was added up to a final volume of $500 \mathrm{~mL}$. HQ solutions $(0.50 \mathrm{mM})$ were prepared in $\mathrm{PB}$. 


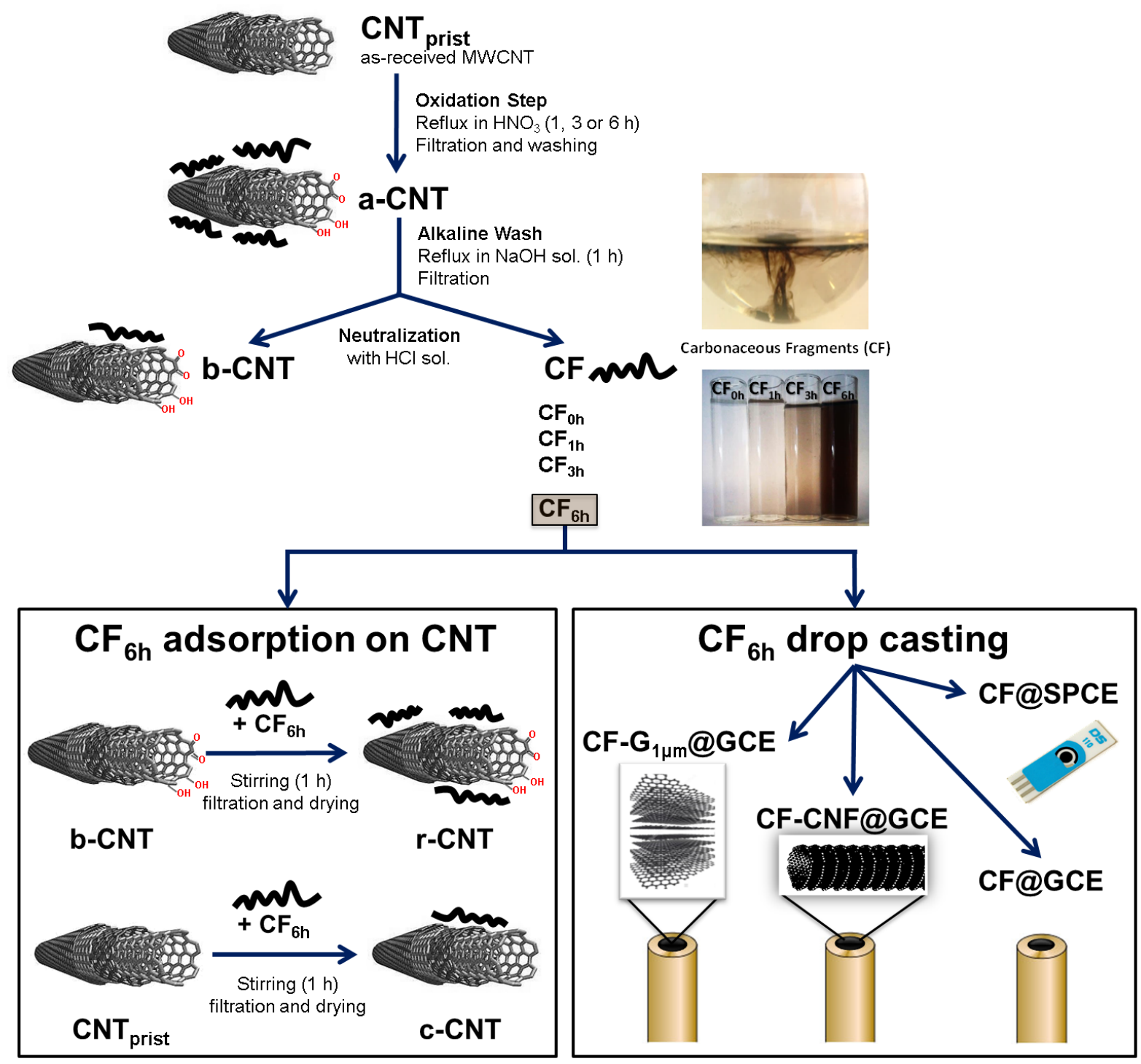

Figure 1. Schematic illustration of: the CNT treatments carried out for the preparation of carbonaceous fragments suspensions (CF); the functionalization of different CNT and of the surface of carbon electrodes with $\mathrm{CF}_{6 \mathrm{~h}}$. $\mathrm{CNT}_{\text {prist: }}$ : pristine $\mathrm{CNT}$; a-CNT: CNT oxidized in $\mathrm{HNO}_{3}$ reflux; b-CNT: obtained by treatment of aCNT with $0.1 \mathrm{M} \mathrm{NaOH}, 1 \mathrm{~h}$ of reflux; c-CNT: $\mathrm{CNT}_{\text {prist }}$ mechanically stirred in $\mathrm{CF}_{6 \mathrm{~h}}$ suspension; r-CNT: b-CNT mechanically stirred in $\mathrm{CF}_{6 \mathrm{~h}}$ suspension. $\mathrm{CF}-\mathrm{G}_{1 \mu \mathrm{m}} @ \mathrm{GCE}$ : GCE coated with graphite powder and modified with $\mathrm{CF}_{6 h}$; CF-CNF@GCE: GCE coated with carbon nanofibers and modified with $\mathrm{CF}_{6 \mathrm{~h}}$; CF@GCE: GCE modified with $\mathrm{CF}_{6 \mathrm{~h}}$; $\mathrm{CF} @ S P C E$ : SPCE modified with $\mathrm{CF}_{6 \mathrm{~h}}$.

The sample for NMR spectroscopy was prepared as follows. The solid sample obtained by complete removal of water from the neutralized solution of $\mathrm{CF}_{6 \mathrm{~h}}$ in a rotary evaporator was a dark grey material containing $\mathrm{CF}_{6 \mathrm{~h}}$ and $\mathrm{NaCl}$ generated in the neutralization process (ca. 80\%). This material was partially solubilized in deuterated water $(30 \mathrm{mg}$ in $600 \mu \mathrm{L}$ ) and the dark grey solid that remained in suspension was filtered through fiber-glass paper. The transparent grey solution was submitted for ${ }^{1} \mathrm{H}$ and ${ }^{13} \mathrm{C}$ NMR spectroscopic analysis. The data for the ${ }^{13} \mathrm{C}$ NMR spectrum was accumulated for $67 \mathrm{~h}$ at $20{ }^{\circ} \mathrm{C}$. During this time period, some dark grey solid was deposited at the bottom of the NMR tube. 


\section{Results and discussion}

\section{Thermal characterization of the different CNT materials}

The CNT, pristine and collected after treatment, were analyzed by thermogravimetric analysis (TGA) and the results are presented in Figure 2. The pristine CNT are stable up to $800^{\circ} \mathrm{C}$ under nitrogen $(1.3 \%$ weight loss), while the oxidized and treated CNT show a significant weight loss. This may be assigned to loss of $\mathrm{CO}$ and $\mathrm{CO}_{2}$ by thermal degradation of the oxidized CNT surface. The weight loss starts above $150{ }^{\circ} \mathrm{C}$ and continues slowly with increasing temperature, showing the thermal decomposition of a variety of oxidation products within a wide range of degradation energies. The overall weight loss at $800{ }^{\circ} \mathrm{C}$ is greater for a-CNT (20.0\%), decreasing after alkali treatment, yielding b-CNT (13.8\%). This weight loss difference correlates with the oxidized debris that are eliminated from a-CNT surface. An increase of weight loss was observed for $\mathrm{r}$-CNT $(15.1 \%)$ relative to $\mathrm{b}-\mathrm{CNT}$ that may be due to re-adsorption of $\mathrm{CF}_{6 \mathrm{~h}}$ from suspension. The c-CNT show a considerable weight loss $(7.3 \%)$ compared to pristine CNT, however smaller than measured for the other oxidized CNT. The amount of $\mathrm{CF}_{6 \mathrm{n}}$ adsorbed by pristine CNT is almost six times larger than the amount adsorbed on b-CNT (formation of $r-C N T$ ), showing the ability of CF to establish $\pi-\pi$ interactions with the pristine CNT. The weight loss also proceeds at slow rate from $150{ }^{\circ} \mathrm{C}$ to $800{ }^{\circ} \mathrm{C}$, demonstrating the chemical similarity of the adsorbed $\mathrm{CF}_{6 \mathrm{~h}}$ with the other oxidized materials. Considering the TGA weight loss observed for a-CNT, b-CNT, and the concentration of a-CNT in the suspensions prepared for alkaline treatment, the concentration of $\mathrm{CF}_{6 \mathrm{~h}}$ formed after treatment is estimated to be approximately $0.8 \mathrm{mg} \mathrm{L}^{-1}$. This value is consistent with the $\mathrm{CF}_{6 \mathrm{~h}}$ concentration estimated from c-CNT weight loss, considering the concentration of pristine $\mathrm{CNT}$ in the $\mathrm{CF}_{6 h}$ suspension used for treatment.

\section{Structural characterization of $\mathrm{CF}$}

The CF were characterized by UV/Vis, fluorescence, FTIR, Raman and NMR spectroscopies. The UV/Vis spectra of $C F$, presented in Figure $3 \mathrm{~A}$, display a peak at low wavelength for all $\mathrm{CF}(\approx 300 \mathrm{~nm})$. For $\mathrm{CF}_{6 \mathrm{~h}}$ suspension, the absorption maximum is higher and a small peak appears at $560 \mathrm{~nm}$. The color of CF suspensions depends on the refluxing time, tending to darker brown as oxidation time increases, indicating an increase of CF concentration (Figure 1).

Fluorescent spectra of CF suspensions displayed strong fluorescence emission at ca. $420 \mathrm{~nm}$ for an excitation wavelength of $290 \mathrm{~nm}$ (Figure 3B). CF suspensions obtained from higher refluxing time with acid, present an increase of fluorescence intensity as well as a shift of the emission peak to higher wavelength. The UV/Vis and fluorescence spectra of CF are similar to those reported in the literature for CF obtained by a similar experimental procedure. ${ }^{[32]}$ This was interpreted by the authors as indicative of the presence of polycyclic aromatic hydrocarbons and conjugated double bonds, with extended oxygen containing functional groups. 


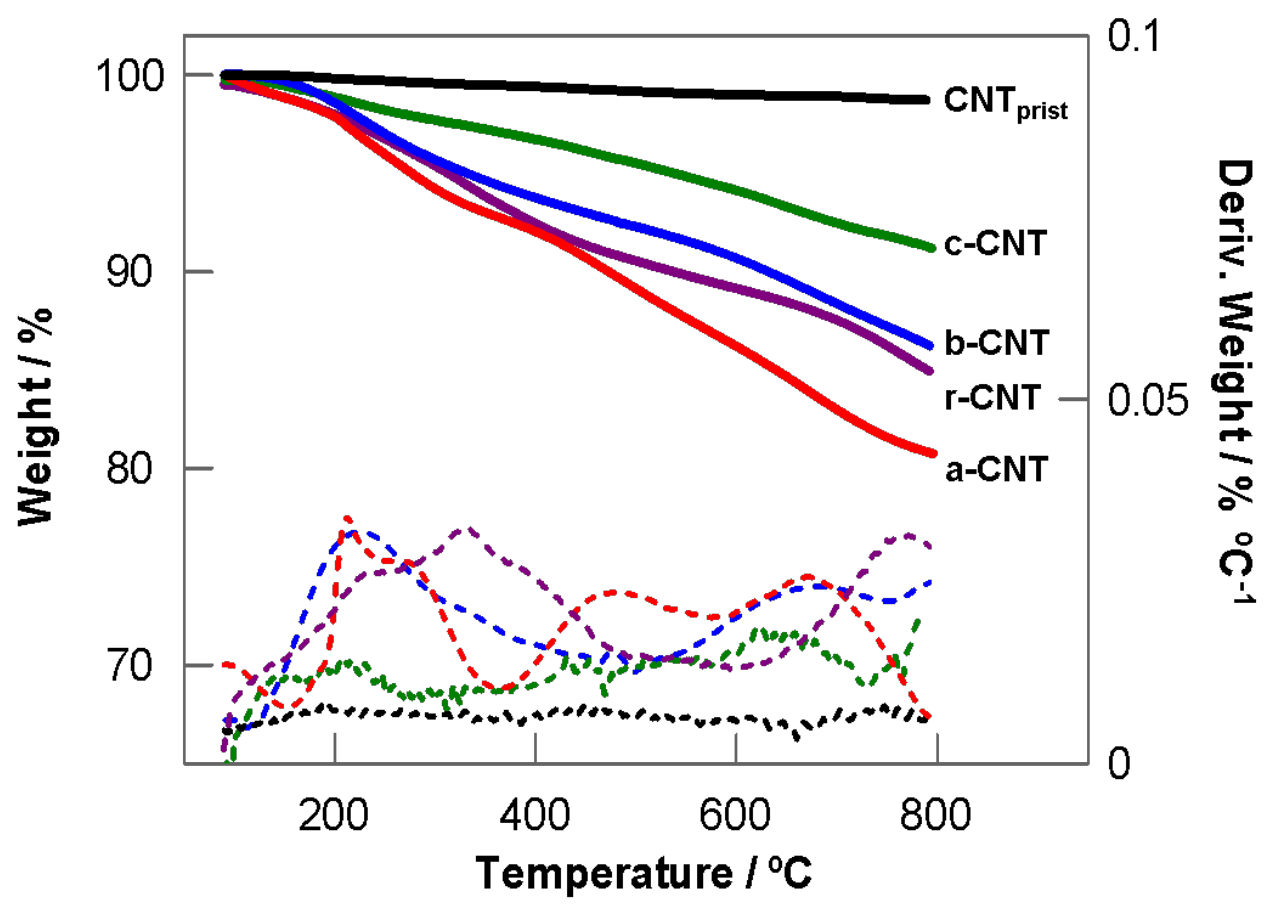

Figure 2. TGA curves and first derivative of $\mathrm{CNT}_{\text {prist }}$, a-CNT, b-CNT, c-CNT and r-CNT.
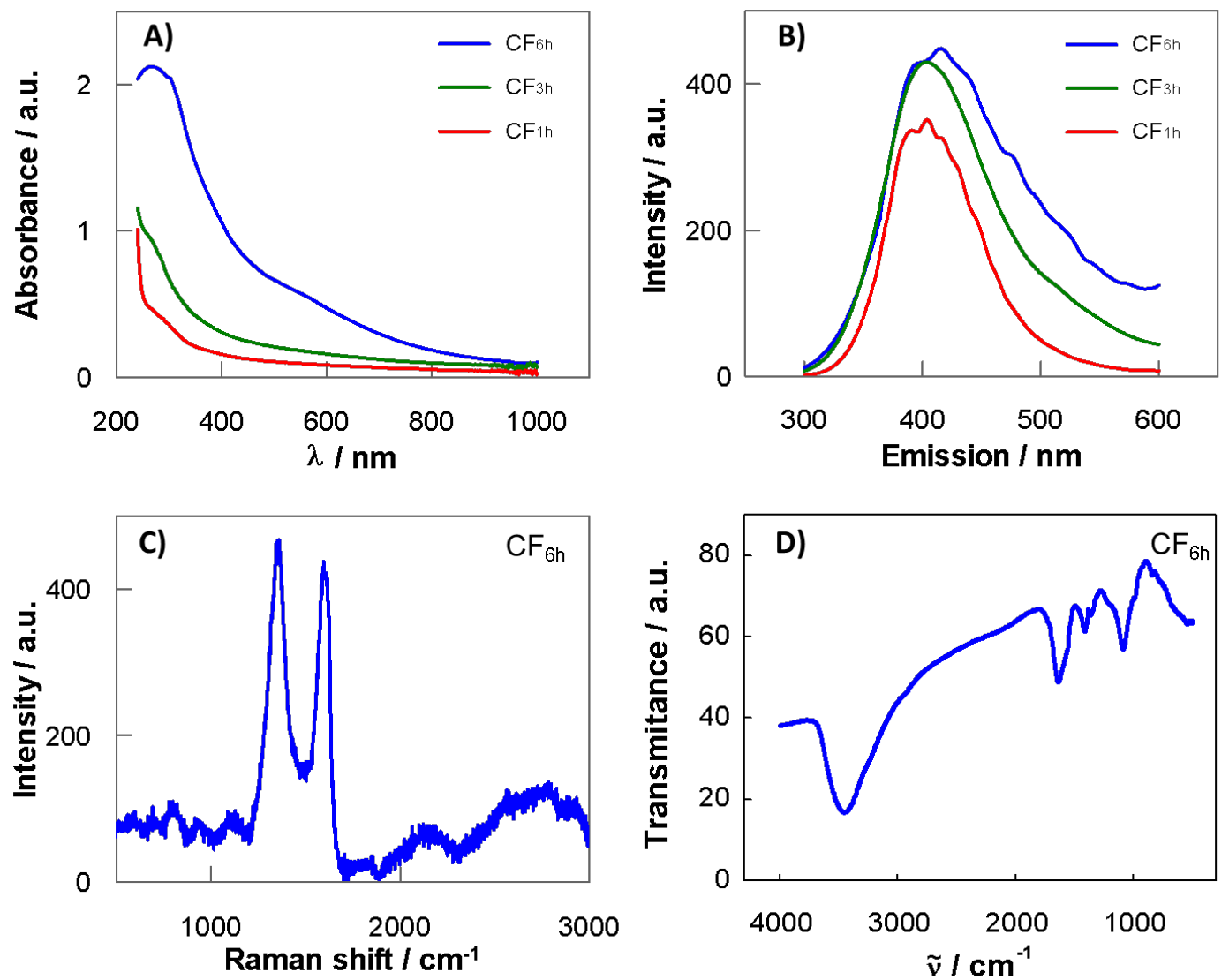

Figure 3. A) UV/Vis spectra of different CF; B) Fluorescence spectra of different CF; C) Raman spectrum of $\mathrm{CF}_{6 n}$; D) FTIR spectrum of $\mathrm{CF}_{6 n}$.

The FTIR spectrum (Figure 3D) confirms the presence of hydroxyl groups by an intense and broad signal at $3380 \mathrm{~cm}^{-1}$, assigned to the stretching vibration of the $\mathrm{O}-\mathrm{H}$ bond. Carbonyl groups in different chemical 
environments can be associated to an equally broad signal spreading from 1695 to $1515 \mathrm{~cm}^{-1}$ and centered at $1615 \mathrm{~cm}^{-1}$. This signal may indicate the presence of conjugated ketones, anhydrides, esters and/or lactones. The $\mathrm{C}=\mathrm{C}$ stretching vibration usually leads to a low intensity signal in this region and the presence of this group can also be considered. The intense band at $1075 \mathrm{~cm}^{-1}$ can be due to the $\mathrm{C}-\mathrm{O}$ stretching vibration in anhydrides, esters and carboxylic acids, supporting their presence in the $\mathrm{CF}_{6 \mathrm{~h}}$.

The Raman spectrum of $\mathrm{CF}_{6 \mathrm{~h}}$ is presented in Figure $3 \mathrm{C}$, showing the characteristic $\mathrm{G}$ and $\mathrm{D}$ peaks of graphite and its derivatives. The $G$ mode, observed in the range of $1500-1630 \mathrm{~cm}^{-1}$ has $E_{2 g}$ symmetry, reflects the in-plane bond stretching motion of pairs of $\mathrm{C} \mathrm{sp}{ }^{2}$ atoms. ${ }^{[45]}$ This mode occurs at all $\mathrm{sp}^{2}$ sites and does not require the presence of six-fold rings. The $D$ mode, observed near $1350 \mathrm{~cm}^{-1}$, is a breathing mode of $A_{1 g}$ symmetry. This is a forbidden mode in perfect graphite, becoming active in the presence of disorder, indicating the existence of a hexagonal $\mathrm{C} \mathrm{sp}{ }^{2}$ network disturbed by chemical bonding and formation of $\mathrm{C} \mathrm{sp^{3 }}$ that reduces the network symmetry. ${ }^{[45]}$ Raman spectra of $\mathrm{CF}_{6 \mathrm{~h}}$ were acquired across a large sample area for statistical analysis (Figure $\mathrm{S} 1$, supporting information) confirming that the $\mathrm{CF}_{6 \mathrm{~h}}$ material structure is based on hexagonal $\mathrm{C} \mathrm{sp}{ }^{2}$ base-material with high disorder induced by chemical bonding, disturbing the perfect symmetry of the graphite structure. Finally, the $2 \mathrm{D}$ band typically detected near $2700 \mathrm{~cm}^{-1}$, observed as a low intensity, wide band ranging from $2500-3000 \mathrm{~cm}^{-1}$, which is characteristic of highly oxidized graphene-type of materials. ${ }^{[46]}$

STEM observation showed small carbonaceous fragments with tens to hundreds of microns of length (illustrative micrographs shown as supporting information). The elemental composition of CF was confirmed by EDS as mainly carbon and oxygen, with a considerable presence of $\mathrm{NaCl}$ resulting from the acid and alkaline treatments applied (supporting information).

The NMR data for the $\mathrm{CF}_{6 \mathrm{~h}}$ was recorded on a very dilute solution, requiring extensive accumulation of the signals in particular for the ${ }^{13} \mathrm{C}$ NMR spectrum. The use of deuterated water as solvent leads to rapid proton-deuterium exchange in the $-\mathrm{OH}$ unit of carboxylic acids and phenolic groups, preventing the visualization of these labile protons in the ${ }^{1} H$ NMR spectrum. Protons bonded to carbon atoms are the only entities that can be identified in the spectrum.

The oxidizing conditions of the experiment may generate functional groups incorporating oxygen, namely hydroxyl, ketone, aldehyde or carboxylic acids. When some of these groups occupy adjacent positions in the molecular assembly, they can evolve to lactones or anhydrides. The formation of these groups was recently identified on the CNT surface, when alkenes were grafted onto CNT and oxidized by heating in sulfuric acid. The extensive formation of adipic anhydride was observed experimentally and theoretical calculations confirmed that this is a favored process either from the exposed alkene, from epoxides, vicinal diols or aldehydes, upon oxidation. ${ }^{[4]}$ 


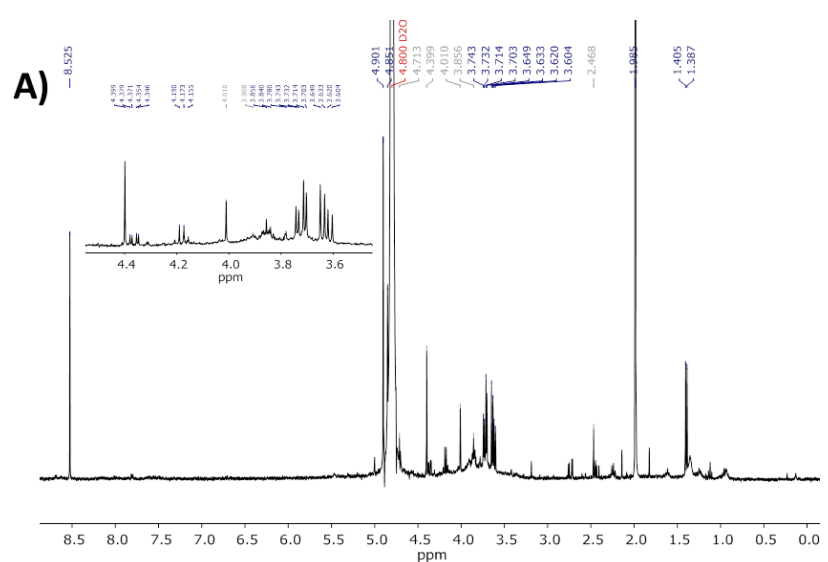

B)

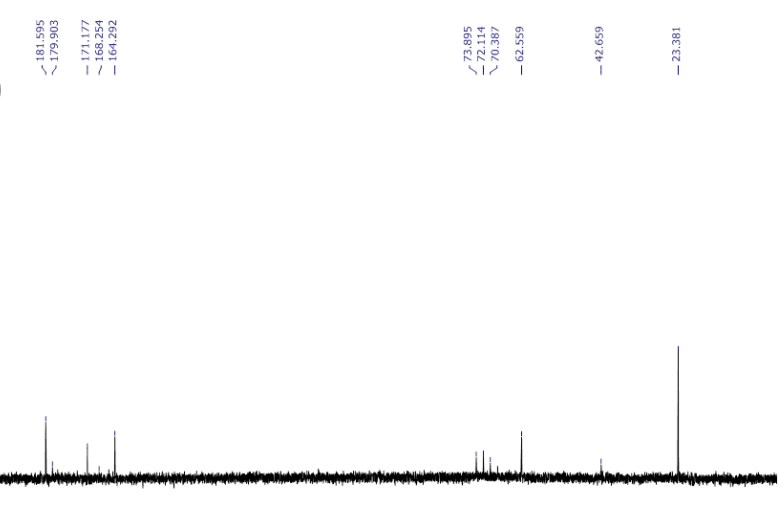

$\begin{array}{llllllllllllllllllll}190 & 180 & 170 & 160 & 150 & 140 & 130 & 120 & 110 & \begin{array}{c}100 \\ \mathrm{ppm}\end{array} & 90 & 80 & 70 & 60 & 50 & 40 & 30 & 20 & 10 & 0\end{array}$

Figure 4. A) ${ }^{1} \mathrm{H}$ NMR $\left(D_{2} \mathrm{O}\right)$ of $\left.\mathrm{CF}_{6 h} ; \mathrm{B}\right){ }^{13} \mathrm{C}$ NMR $\left(\mathrm{D}_{2} \mathrm{O}\right)$ of $\mathrm{CF}_{6 h}$.

Combining the experimental conditions with the ${ }^{1} \mathrm{H}$ NMR spectroscopic evidence (Figure 4A), we can identify a minute amount of equivalent aromatic protons (sharp singlet at $\delta 8.53 \mathrm{ppm}$ ) as most of the signals are generated by aliphatic protons $(\delta 1-4.5 \mathrm{ppm})$. The presence of signals in the $\delta 3.5-4.5 \mathrm{ppm}$ region indicates that aliphatic protons are in the vicinity of electron-withdrawing hydroxyl groups and / or the oxygen atom of lactones. This assignment is supported by ${ }^{13} \mathrm{C}$ NMR (Figure 4B) that shows signals at $\delta$ $73.89,72.11,70.38$ and $68.54 \mathrm{ppm}$, compatible with this type of substitution in slightly different chemical environments. The DEPT 135 experiment (in Figure S2) confirms that these signals correspond to a single proton linked to the $\mathrm{sp}^{3}$ carbon. The same technique identifies the signal at $\delta 62.55 \mathrm{ppm}$ as that of a $\mathrm{CH}_{2}$ group, possibly linked to the oxygen atom of a lactone. The signal at $\delta 171.17 \mathrm{ppm}$ can be assigned to the corresponding carbonyl group. Signals in the $\delta 1-3 \mathrm{ppm}$ region correspond to more shielded aliphatic protons bonded to carbon atoms in the vicinity of carbonyl groups or inserted in a carbon chain or ring. The intense signal at $\delta 23.8 \mathrm{ppm}$ in the ${ }^{13} \mathrm{C}$ NMR can also be assigned either to a methyl group or to a $\mathrm{C}-\mathrm{H}$ carbon inserted in a carbon chain (by DEPT 135). The presence of carboxylic acids and / or anhydrides cannot be excluded as the intense signal at $\delta 164.29 \mathrm{ppm}$ and the minor peak at $\delta 168.25 \mathrm{ppm}$ are compatible with such carbonyl carbon atoms. The intense peak at $\delta 181.59 \mathrm{ppm}$ and less intense peaks in its vicinity may be due to quinone-type carbonyl groups. The DEPT 135 technique confirms that none of these carbonyl groups is linked to a proton, confirming that the aldehyde function is either absent or is a negligible component in the $\mathrm{CF}_{6 \mathrm{~h}}$ material.

\section{The role of CF on the voltammetric properties of CNT}

The voltammetric characterization of the different CNT materials was performed after their immobilization at the surface of a GCE by drop casting and further evaporation of solvent, as described in the experimental section. The cyclic voltammograms acquired in PB solutions are displayed in Figure 5. The voltammograms

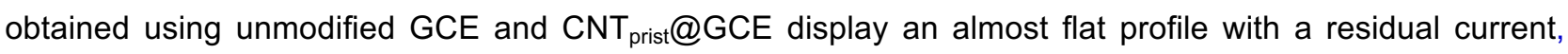
while those from a-CNT, b-CNT, c-CNT and r-CNT exhibit a current response over the whole potential range. At the potential range from $-0.5 \mathrm{~V}$ to $0 \mathrm{~V}$, ascribed to the oxidation/ reduction of quinoid groups ${ }^{[48-50]}$ only the voltammograms obtained from a-CNT@GCE and r-CNT@GCE display a significant current. 
The voltammetry of $\mathrm{HQ}$ at CNT modified GCE provides important insight on the presence of oxo-surface groups. The possible interaction of $\mathrm{C}-\mathrm{OH}$ groups (reduced form of $\mathrm{HQ}$ ) and of $\mathrm{C}=\mathrm{O}$ groups (oxidized form of $H Q$ ) with the oxo-surface groups may modify the voltammetric response of $H Q$. $H Q$ is oxidized by a slow electron transfer process involving a two electron - two $\mathrm{H}^{+}$mechanism and its oxidized form can be reduced back. $^{[22,51]}$ The heterogeneous rate constant for $\mathrm{HQ}$ oxidation is quite sensitive to the interface structure and hence the voltammetric profile depends on the electrode nature.
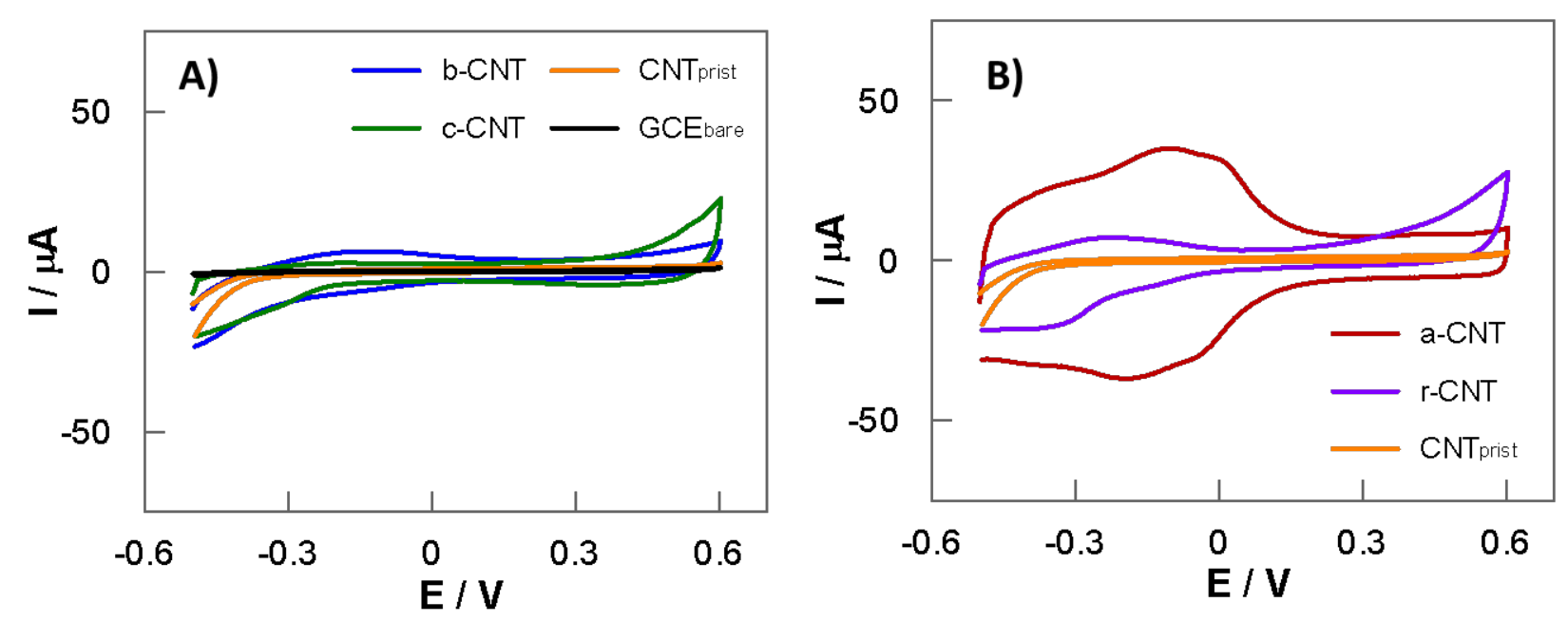

Figure 5. Voltammetric characterization of: A) unmodified GCE (GCE $E_{\text {bare}}$ ) and GCE modified with b-CNT, cCNT and $\mathrm{CNT}_{\text {prist }}$; B) GCE modified with a-CNT, r-CNT and $\mathrm{CNT}_{\text {prist }}$ in a PB pH 7.2 solution.

Voltammograms of $\mathrm{HQ}$ obtained with $\mathrm{CNT}_{\text {prist }} @ G C E$ show an important potential shift of the anodic peak to less positive potentials with regard to voltammograms from GCE (Figure 6A). Deeper modifications are noticed when a-CNT@GCE is used, as in addition to the shift of the anodic peak, anodic and cathodic currents increase markedly (Figure 6B). This indicates that $\mathrm{HQ}$ interacts with the oxygen groups on the aCNT surface. Furthermore, the increase of peaks current ratio, $i_{p}{ }^{a} / i_{p}{ }^{c}$, from 1.0 (for GCE and CNT prist@GCE) to 1.6 (for a-CNT@GCE) (Table 1) suggests that the interactions are stronger with the reduced form of $\mathrm{HQ}$ than with the oxidized form. This result may be a consequence of the presence of quinoid units on a-CNT. The oxidation of these quinoid units at a potential lower than that of $H Q$ leads to the conversion of phenolic groups to quinones. The consequent increase of $\mathrm{C}=\mathrm{O}$ with respect to $\mathrm{C}-\mathrm{OH}$ groups may enhance the interaction with the reduced form of $\mathrm{HQ}$ by hydrogen bonds.

In order to characterize the role of CF on the electrochemical behavior of oxidized CNT, voltammograms were recorded using b-CNT (prepared from a-CNT by reflux in $\mathrm{NaOH}$ solution), and c-CNT, (prepared from $\mathrm{CNT}_{\text {prist }}$ that were in contact with CF suspension). Using either b-CNT@GCE or c-CNT@GCE the anodic and cathodic peaks of $H Q$ are similar, displaying $i_{p}{ }^{a} / i_{p}{ }^{c}$ close to 1.0 (Table 1). 

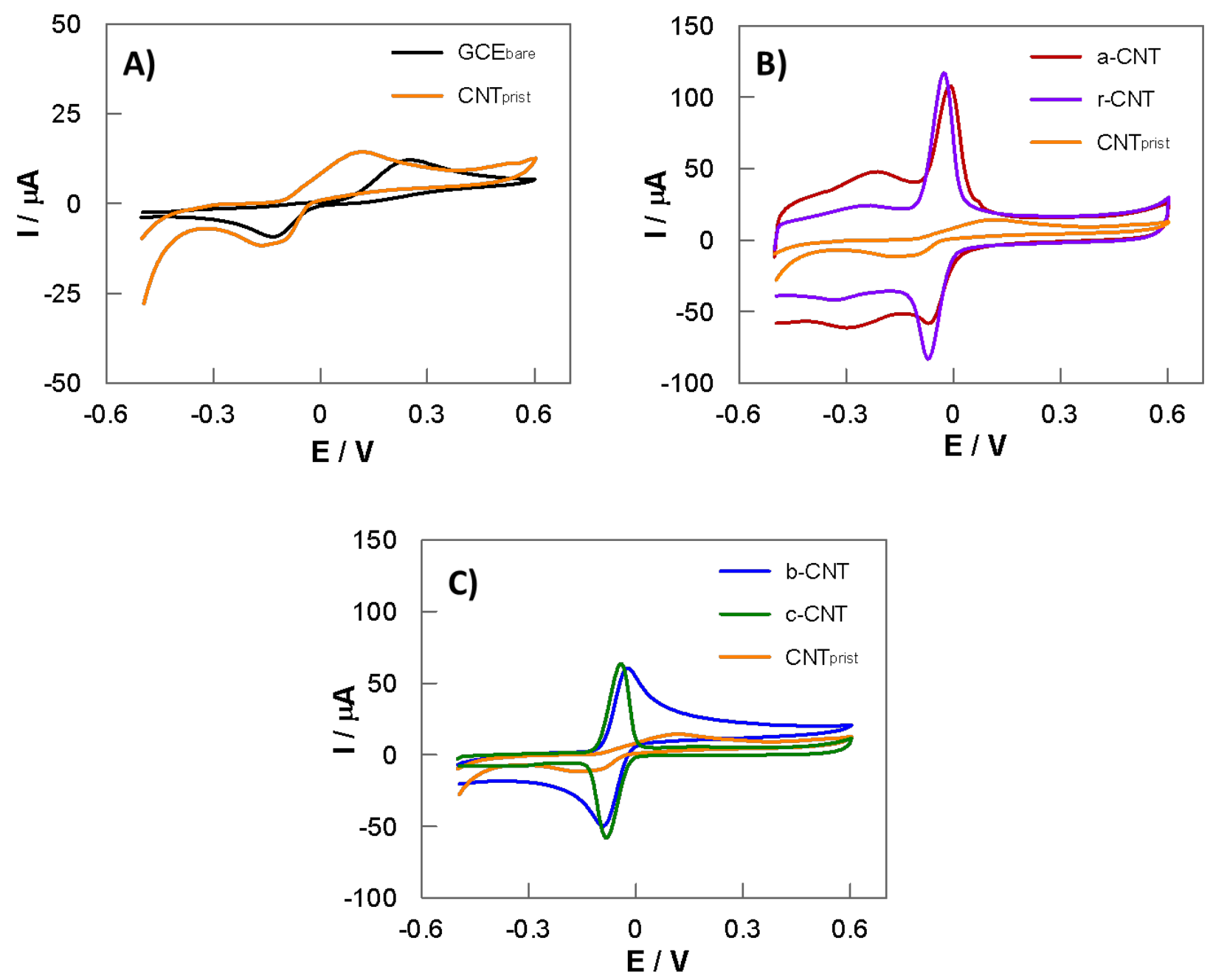

Figure 6. Voltammetric responses of $0.50 \mathrm{mM} \mathrm{HQ}$ in $\mathrm{PB}$ solution $\mathrm{pH} 7.2$ using: $\mathrm{A})$ bare $\mathrm{GCE}$ and CNT pris @GCE; B) a-CNT@GCE, r-CNT@GCE and CNT pris@@GCE; C) b-CNT@GCE, c-CNT@GCE and CNT prist@GCE.

Table 1. Characteristic parameters of the voltamogramms displayed in Figure 6.

\begin{tabular}{ccccc}
\hline Electrode & $\begin{array}{c}\Delta \mathrm{E}_{\mathrm{p}}\left(\mathrm{E}_{\mathrm{p}}{ }^{\mathrm{a}}-\mathrm{E}_{\mathrm{p}}{ }^{\mathrm{c}}\right) \\
(\mathrm{mV})\end{array}$ & $\mathrm{i}_{\mathrm{p}}{ }^{a} / \mathrm{i}_{\mathrm{p}}{ }^{\mathrm{c}}$ & $\begin{array}{c}\mathrm{E}_{\mathrm{p}}{ }^{\mathrm{a}}-\left(\mathrm{E}_{\mathrm{p}}{ }^{\mathrm{a}}\right)_{\mathrm{GCE}} \\
(\mathrm{mV})\end{array}$ & $\mathrm{i}_{\mathrm{p}}{ }^{a} /\left(\mathrm{i}_{\mathrm{p}}{ }^{\mathrm{a}}\right)_{\mathrm{GCE}}$ \\
\hline GCE & 389 & 1.0 & 0 & 1 \\
CNT prist $@ G C E_{\mathrm{a}-\mathrm{CNT} @ G C E}$ & 230 & 1.1 & -144 & 1.3 \\
b-CNT@GCE & 64 & 1.6 & -241 & 9.8 \\
C-CNT@GCE & 58 & 1.0 & -286 & 7.4 \\
r-CNT@GCE & 44 & 1.1 & -295 & 8.0 \\
\hline
\end{tabular}

The distinct voltammetric responses of c-CNT and r-CNT (obtained by adsorption of CF on $\mathrm{CNT}_{\text {prist }}$ and bCNT, respectively) indicate that the electrochemical behavior of $\mathrm{CF}$ is highly influenced by the interactions with the CNT surface. With the pristine CNT, the association is dominated by $\pi-\pi$ interactions, with the polar groups of CF oriented towards the solution. The functionalization maintained on the b-CNT surface may be involved in polar and $\mathrm{H}$-bond interactions with the extensively oxidized $\mathrm{CF}$ surface. In particular, the $\mathrm{C}-\mathrm{OH}$ 
and $\mathrm{C}=\mathrm{O}$ groups of carboxylic acids may be involved in the generation of supramolecular arrangements. The presence of $\mathrm{C}-\mathrm{OH}$ groups from $\mathrm{CF}$ and from b-CNT in neighboring positions may lead to molecular assemblies that mimic the electrochemical behavior of the quinoid units. The response pattern previously assigned to quinoid units in a-CNT (in the range of -0.5 to $0 \mathrm{~V}$ ) is not evident in the voltammogram of b-CNT (Figure 5A and Figure $6 \mathrm{C}$ ) and reappears on the voltammogram of $\mathrm{r}$-CNT (Figure 5B and Figure 6B). The disruption and regeneration of these structures in an almost reversible manner reflects the labile nature of these supramolecular arrangements.

The response of HQ using r-CNT@GCE is different from the obtained with either b-CNT@GCE or cCNT@GCE. The peaks asymmetry characterized by $i_{p}{ }^{a} / i_{p}{ }^{c}=1.4$, although lower, resemble that observed for a-CNT@GCE $\left(i_{p}{ }^{a} / i_{p}{ }^{c}=1.6\right)$. Voltammograms from $r-C N T$ also display the typical response of quinoid units previously described for a-CNT.

Another important feature associated to the presence of CF is its role on the adsorption of $\mathrm{HQ}$. While voltammograms from a-CNT display a typical peak of an adsorption-controlled process (Figure 6B, a-CNT), voltammograms from b-CNT exhibit a shape typical of a diffusion-controlled process (Figure 6C, b-CNT). Voltammograms from c-CNT (Figure 6C, c-CNT) and from r-CNT (obtained by CF adsorbed on b-CNT) (Figure 6B, r-CNT) present the typical adsorption-controlled response. Thus, the CF present on a-CNT, cCNT and r-CNT are likely to provide the active sites for adsorption of both reduced and oxidized forms of $\mathrm{HQ}$. These evidences indicate that $\mathrm{CF}$ is an interesting material that can be used to tailor the surface of electrode to interact with specific molecules, facilitating the electron transfer process.

\section{Voltammetric characterization of $\mathrm{CF}_{6 h}$ modified carbon electrodes}

The suspension of $\mathrm{CF}_{6 \mathrm{~h}}\left(0.8 \mathrm{mg} \mathrm{L}^{-1}\right)$ was used to modify the surface of electrodes of different carbon materials, namely, SPCE, GCE, GCE coated with graphite powder $\left(\mathrm{G}_{1 \mu \mathrm{m}} @ \mathrm{GCE}\right)$ and GCE coated with carbon nanofibers (CNF@GCE). The voltammetric responses of HQ using these electrodes are displayed in Figure 7. As a general trend, the voltammetric curves show improved features when CF are drop casted on the electrodes surface. A marked shift of the peaks potential is visible, leading to the decrease of the $\Delta E p$ $\left(E_{p}{ }^{a}-E_{p}{ }^{c}\right)$ and the shape of voltammograms becomes steeper (Table 2). These effects indicate that CF have important catalytic properties. For all electrodes an increase of current ranging from 30 to $180 \%$ is observed depending on the micro / nano-structuration of the surface. The lower current increase, ca. $30 \%$, was observed for the smoother surface of glassy carbon, followed by the graphitic surfaces of SPCE and $\mathrm{G}_{1 \mu \mathrm{m}} @ G C E$, with a $60 \%$ increase. The nanostructured surface of CNF@GCE, (CNF with 60-100 nm diameter), display a $180 \%$ current increase. This trend is also observed c-CNT@GCE (Figure 6B). The CNT diameter is approximately $9.5 \mathrm{~nm}$, and the measured current increases ca. $600 \%$, from $\mathrm{CNT}_{\text {prist }}$ to cCNT (Table 1). Besides, the shape of the voltammogram of CF-CNF@GCE deviates from a diffusioncontrolled to an adsorption-controlled process, as previously remarked for c-CNT. 

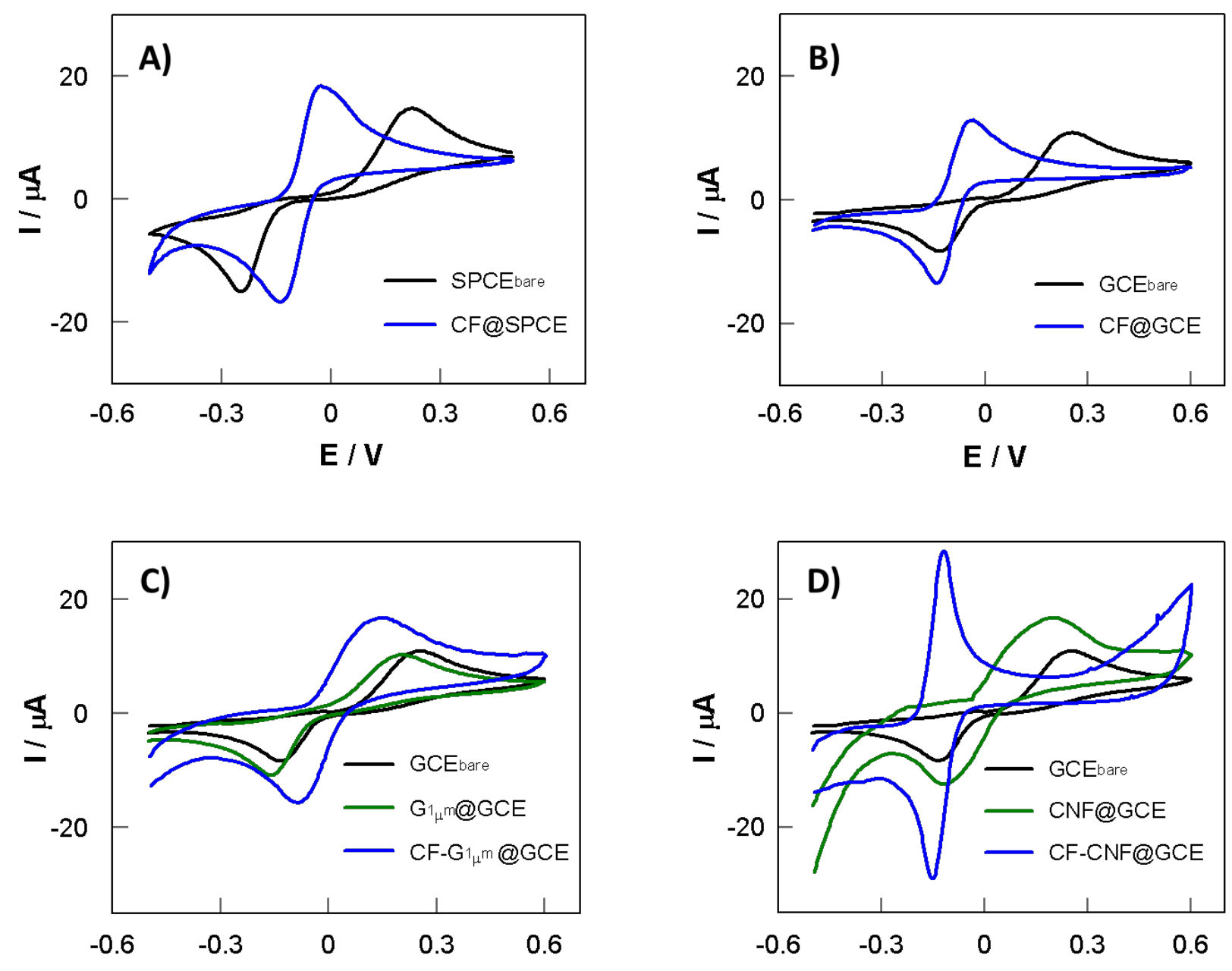

E / V

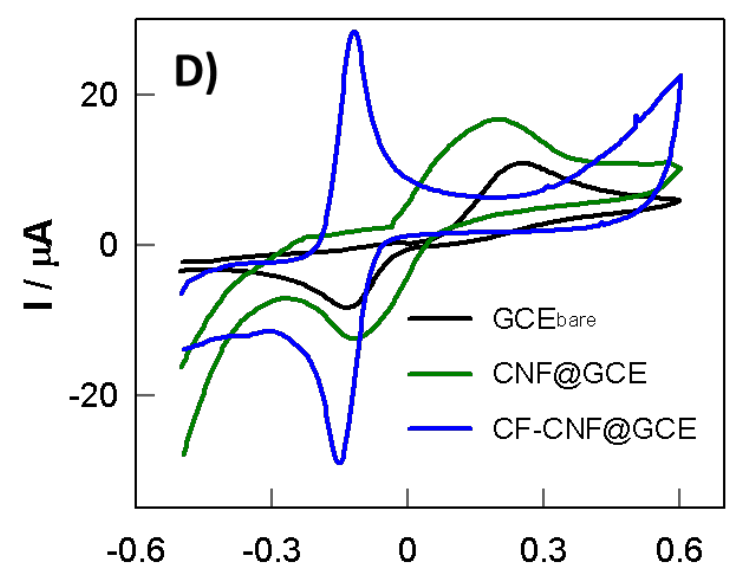

Figure 7. Voltammetric characterization of different carbon electrodes modified with $\mathrm{CF}_{6 \mathrm{~h}}$ obtained in a 0.50 mM of HQ, 0.15 M PB pH 7.2. A) SPCE; B) GCE; C) $G_{1 \mu m} @ G C E$ and D) CNF@GCE.

Table 2. Characteristic parameters of the voltamogramms displayed in Figure 7.

\begin{tabular}{|c|c|c|c|c|c|c|}
\hline \multirow[t]{2}{*}{ Electrode } & \multicolumn{2}{|c|}{$\begin{array}{c}\Delta E_{p}\left(E_{p}^{a}-E_{p}^{c}\right) \\
(m V)\end{array}$} & \multirow[t]{2}{*}{$\begin{array}{c}\left(E_{p}{ }^{a}\right)_{\text {with }} C F-\left(E_{p}{ }^{a}\right)_{\text {without } C F} \\
(m V)\end{array}$} & \multicolumn{2}{|c|}{$i_{p}^{a} / i_{p}^{c}$} & \multirow[t]{2}{*}{$\left(\mathrm{i}_{\mathrm{p}}^{\mathrm{a}}\right)_{\text {with CF}} /\left(\mathrm{i}_{\mathrm{p}}^{\mathrm{a}}\right)_{\text {without CF }}$} \\
\hline & without CF & with CF & & without CF & with CF & \\
\hline SPCE & 459 & 103 & -244 & 0.9 & 1.1 & 1.6 \\
\hline GCE & 389 & 83 & -300 & 1.0 & 0.9 & 1.3 \\
\hline $\mathrm{G}_{1 \mu \mathrm{m}} @ G C E$ & 342 & 215 & -127 & 0.9 & 0.9 & 1.6 \\
\hline CNF@GCE & 273 & 29 & -288 & 0.9 & 1.2 & 2.8 \\
\hline
\end{tabular}

\section{Conclusion}

The CF obtained by oxidation of CNT were characterized by spectroscopic techniques and visualized by STEM. Fluorescence and Raman spectroscopies indicate the presence of alkenes and graphene-type conjugated aromatic rings, with highly oxidized moieties. The presence of alcohols and carbonyl groups, 
some of them associated to aliphatic fragments and probably incorporated as phenols, quinones, lactones, anhydrides and carboxylic acids, is supported by FTIR and NMR spectroscopy.

Our results demonstrate that CF have the ability to strongly adsorb on carbon-based surfaces with different functionalization level. CF adsorbs on $\mathrm{CNT}_{\text {prist }}$ and on oxidized CNT (b-CNT) yielding c-CNT and r-CNT, respectively. These CNT materials displayed dissimilar voltammetric response demonstrating that the interaction between CF and the CNT surface, as well as the chemistry of the underlying CNT surface, play a fundamental role on the voltammetric response of these materials.

The CF-modified CNT revealed important electrocatalytic effects observed by changes in the shape of $\mathrm{HQ}$ voltammograms, potential shifts, and current increase. The electrodes that were modified with CFcontaining CNT, namely a-CNT, C-CNT and r-CNT, display a voltammetric response for HQ typical of adsorption-controlled processes, while electrodes modified with b-CNT (prepared by removing CF from aCNT) display a typical diffusion-controlled response. Therefore, the active sites for $\mathrm{HQ}$ adsorption strongly correlate with the presence of $\mathrm{CF}$.

Our results indicate that the voltammetric behavior of CF is highly influenced by their interaction with CNT surface. The CF association with the pristine CNT may be dominated by $\pi-\pi$ interactions, while with oxidized CNT it may involve polar and $\mathrm{H}$-bond interactions. In particular, the strong $\mathrm{H}$-bond involving $\mathrm{C}-\mathrm{OH}$ and $\mathrm{C}=\mathrm{O}$ groups of carboxylic acids generate supramolecular arrangements that mimic the electrochemical response of quinoid units. The disruption (by alkali treatment of a-CNT) and regeneration (by adsorption of CF on b-CNT) of these structures in an almost reversible manner reflects the labile nature of these supramolecular arrangements.

In voltammetric experiment these quinoid units on the CNT surface are oxidized, decreasing the concentration of $\mathrm{C}-\mathrm{OH}$ groups by conversion to $\mathrm{C}=\mathrm{O}$ groups. The more extensive interaction of the reduced form of $\mathrm{HQ}$ with the electrochemically oxidized electrode surface is demonstrated by the higher anodic relative to the cathodic peak.

The use of CF for the functionalization of carbon electrodes was evaluated for the detection of $\mathrm{HQ}$ as a model polyphenol. Voltammograms from modified glassy carbon, graphite and carbon nanofiber electrodes exhibited improved responses with regard to $H Q$ oxidation. The magnitude of the effects depended strongly on the electrode surface roughness, the rougher surfaces presenting the higher effects.

\section{Acknowledgements}

Thanks are due to FCT and COMPETE-QREN-EU for financial support: project PEst-/QUI/UI0686/2013 (Research Centre CQ/UM) and project PEst-C/CTM/LA0025/2013 (IPC/I3N). RG and EC thank the FCT, POCH and ESF for his Post- Doc (SFRH/BPD/86690/2012) and hers Ph.D. grant (SFRH/BD/87214/2012) respectively. 
Figure 1. Schematic illustration of: the CNT treatments carried out for the preparation of carbonaceous fragments suspensions (CF); the functionalization of different CNT and of the surface of carbon electrodes with $\mathrm{CF}_{6 \mathrm{~h}}$. $\mathrm{CNT}_{\text {prist: }}$ pristine $\mathrm{CNT}$; a-CNT: CNT oxidized in $\mathrm{HNO}_{3}$ reflux; b-CNT: obtained by treatment of aCNT with $0.1 \mathrm{M} \mathrm{NaOH}, 1 \mathrm{~h}$ of reflux; c-CNT: $\mathrm{CNT}_{\text {prist }}$ mechanically stirred in $\mathrm{CF}_{6 \mathrm{~h}}$ suspension; $\mathrm{r}-\mathrm{CNT}$ : b-CNT

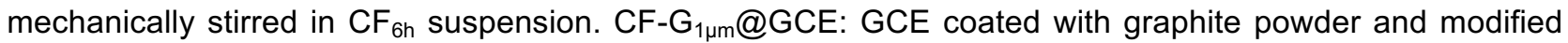
with $\mathrm{CF}_{6 \mathrm{~h}}$; CF-CNF@GCE: GCE coated with carbon nanofibers and modified with $\mathrm{CF}_{6 \mathrm{~h}}$; CF@GCE: GCE modified with $\mathrm{CF}_{6 h}$; $\mathrm{CF} @ S P C E$ : SPCE modified with $\mathrm{CF}_{6 \mathrm{~h}}$.

Figure 2. TGA curves and first derivative of $\mathrm{CNT}_{\text {prist, }} \mathrm{a}-\mathrm{CNT}$, b-CNT, c-CNT and r-CNT.

Figure 3. A) UV/Vis spectra of different CF; B) Fluorescence spectra of different CF; C) Raman spectrum of $\left.\mathrm{CF}_{6 h} ; \mathrm{D}\right) \mathrm{FTIR}$ spectrum of $\mathrm{CF}_{6 \mathrm{~h}}$.

Figure 4. A) ${ }^{1} \mathrm{H}$ NMR $\left(D_{2} \mathrm{O}\right)$ of $\left.\mathrm{CF}_{6 h} ; \mathrm{B}\right){ }^{13} \mathrm{C}$ NMR $\left(\mathrm{D}_{2} \mathrm{O}\right)$ of $\mathrm{CF}_{6 h}$.

Figure 5. Voltammetric characterization of: A) unmodified GCE (GCE bare) and GCE modified with b-CNT, cCNT and $\mathrm{CNT}_{\text {prist }}$; B) GCE modified with a-CNT, r-CNT and CNT prist in a PB pH 7.2 solution.

Figure 6. Voltammetric responses of $0.50 \mathrm{mM} \mathrm{HQ}$ in $\mathrm{PB}$ solution $\mathrm{pH} 7.2$ using: A) bare $\mathrm{GCE}$ and CNT prist@GCE; B) a-CNT@GCE, r-CNT@GCE and CNT pris@@GCE; C) b-CNT@GCE, c-CNT@GCE and CNT prist@GCE.

Figure 7. Voltammetric characterization of different carbon electrodes modified with $\mathrm{CF}_{6 \mathrm{~h}}$ obtained in a 0.50 mM of HQ, 0.15 M PB pH 7.2. A) SPCE; B) GCE; C) $G_{1 \mu m} @ G C E$ and D) CNF@GCE.

\section{References}

[1] W. Zhang, S. Zhu, R. Luque, S. Han, L. Hu, G. Xu, Chem. Soc. Rev. 2016, 45, 715-752.

[2] S. Marchesan, M. Melchionna, M. Prato, ACS Nano 2015, 9, 9441-9450.

[3] A. Ambrosi, C. K. Chua, N. M. Latiff, A. H. Loo, C. H. A. Wong, A. Y. S. Eng, A. Bonanni, M. Pumera, Chem. Soc. Rev. 2016, 45, 2458-2493.

[4] A. Martín, A. Escarpa, TrAC Trends Anal. Chem. 2014, 56, 13-26.

[5] W. Gao, Y. Wan, Y. Dou, D. Zhao, Adv. Energy Mater. 2011, 1, 115-123.

[6] C. E. Banks, R. G. Compton, Analyst 2006, 131, 15-21.

[7] C. E. Banks, A. Crossley, C. Salter, S. J. Wilkins, R. G. Compton, Angew. Chemie - Int. Ed. 2006, 45, 2533-2537.

[8] M. C. Henstridge, L. Shao, G. G. Wildgoose, R. G. Compton, G. Tobias, M. L. H. Green, Electroanalysis 2008, 20, 498-506.

[9] X. Chia, A. Ambrosi, M. Pumera, Electrochem. Commun. 2014, 38, 1-3.

[10] L. Wang, A. Ambrosi, M. Pumera, Electrochem. Commun. 2013, 26, 71-73.

[11] L. Wang, A. Ambrosi, M. Pumera, Anal. Chem. 2013, 85, 6195-6197.

[12] A. Ambrosi, M. Pumera, Chem. - A Eur. J. 2010, 16, 10946-10949.

[13] A. Ambrosi, M. Pumera, J. Phys. Chem. C 2011, 115, 25281-25284.

[14] E. L. K. Chng, M. Pumera, Chem. - A Eur. J. 2012, 18, 1401-1407.

[15] D. A. C. Brownson, C. E. Banks, Electrochem. Commun. 2011, 13, 111-113. 
[16] R. Gusmão, Z. Sofer, M. Novacek, J. Luxa, S. Matejkova, M. Pumera, Nanoscale 2016, 8, 67006711.

[17] D. V Kosynkin, A. L. Higginbotham, A. Sinitskii, J. R. Lomeda, A. Dimiev, B. K. Price, J. M. Tour, Nature 2009, 458, 872-876.

[18] W. S. Hummers, R. E. Offeman, J. Am. Chem. Soc. 1958, 80, 1339-1339.

[19] M. N. Tchoul, W. T. Ford, G. Lolli, D. E. Resasco, S. Arepalli, Chem. Mater. 2007, 19, 5765-5772.

[20] I. D. Rosca, F. Watari, M. Uo, T. Akasaka, Carbon N. Y. 2005, 43, 3124-3131.

[21] M. Thiruppathi, N. Thiyagarajan, M. Gopinathan, J.-M. Zen, Electrochem. Commun. 2016, 69, 1518.

[22] R. Gusmão, V. López-Puente, I. Pastoriza-Santos, J. Pérez-Juste, M. F. Proença, F. Bento, D. Geraldo, M. C. Paiva, E. Gonzalez-Romero, RSC Adv. 2015, 5, 5024-5031.

[23] K. Jurkschat, X. Ji, A. Crossley, R. G. Compton, C. E. Banks, Analyst 2007, 132, 21-23.

[24] H. Hu, B. Zhao, M. E. Itkis, R. C. Haddon, J. Phys. Chem. B 2003, 107, 13838-13842.

[25] U. Anik, S. Cevik, M. Pumera, Nanoscale Res. Lett. 2010, 5, 846-852.

[26] A. Ambrosi, C. K. Chua, B. Khezri, Z. Sofer, R. D. Webster, M. Pumera, Proc. Natl. Acad. Sci. 2012, 109, 12899-12904.

[27] S. Fogden, R. Verdejo, B. Cottam, M. Shaffer, Chem. Phys. Lett. 2008, 460, 162-167.

[28] J. P. Rourke, P. A. Pandey, J. J. Moore, M. Bates, I. A. Kinloch, R. J. Young, N. R. Wilson, Angew. Chemie - Int. Ed. 2011, 50, 3173-3177.

[29] R. Verdejo, S. Lamoriniere, B. Cottam, A. Bismarck, M. Shaffer, Chem. Commun. 2007, 513-515.

[30] C. G. Salzmann, S. A. Llewellyn, G. Tobias, M. A. H. Ward, Y. Huh, M. L. H. Green, Adv. Mater. 2007, 19, 883-887.

[31] K. A. Worsley, R. W. Kondrat, S. K. Pal, I. Kalinina, R. C. Haddon, Carbon N. Y. 2011, 49, 49824986.

[32] X. Ma, L. Jia, L. Zhang, L. Zhu, Chem. - Eur. J. 2014, 20, 4072-4076.

[33] D. Ma, L. Dong, M. Zhou, L. Zhu, Analyst 2016, 2761-2766.

[34] X. Li, X. Yang, L. Jia, X. Ma, L. Zhu, Electrochem. Commun. 2012, 23, 94-97.

[35] X. Li, D. Ma, L. Zhu, Chem. - A Eur. J. 2015, 21, 17239-17244.

[36] X. Yang, X. Li, X. Ma, L. Jia, L. Zhu, RSC Adv. 2013, 3, 6752-6755.

[37] X. Yang, X. Li, X. Ma, L. Jia, L. Zhu, Electroanalysis 2014, 26, 139-146.

[38] A. Bonanni, A. Ambrosi, C. K. Chua, M. Pumera, ACS Nano 2014, 8, 4197-4204.

[39] L. Wang, A. Ambrosi, M. Pumera, Chem. - An Asian J. 2013, 8, 1200-1204.

[40] D. Stéfani, A. J. Paula, B. G. Vaz, R. A. Silva, N. F. Andrade, G. Z. Justo, C. V Ferreira, A. G. S. Filho, M. N. Eberlin, O. L. Alves, J. Hazard. Mater. 2011, 189, 391-396.

[41] J. Zhong, T. Xie, J. Deng, X. Sun, X. Pan, X. Bao, Z. Wu, Chem. Commun. 2011, 47, 8373-8375.

[42] G. Busca, S. Berardinelli, C. Resini, L. Arrighi, J. Hazard. Mater. 2008, 160, 265-288.

[43] K. B. Pandey, S. I. Rizvi, Oxid. Med. Cell. Longev. 2009, 2, 270-278.

[44] C. A. Rice-Evans, N. J. Miller, G. Paganga, Free Radic. Biol. Med. 1996, 20, 933-956.

[45] A. C. Ferrari, J. Robertson, Phys. Rev. B 2000, 61, 14095-14107.

[46] D. Yang, A. Velamakanni, G. Bozoklu, S. Park, M. Stoller, R. D. Piner, S. Stankovich, I. Jung, D. A. 
Field, C. A. Ventrice Jr., R. S. Ruoff, Carbon N. Y. 2009, 47, 145-152.

[47] R. F. Araújo, M. F. Proença, C. J. Silva, T. G. Castro, M. Melle-Franco, M. C. Paiva, S. Villar-Rodil, J. M. D. Tascón, Carbon N. Y. 2016, 98, 421-431.

[48] Y. Xing, L. Li, C. C. Chusuei, R. V Hull, Langmuir 2005, 21, 4185-4190.

[49] R. Gusmão, M. Melle-Franco, D. Geraldo, F. Bento, F. Proença, M. C. Paiva, Electrochem. Commun. 2015, 57, 22-26.

[50] C. A. Thorogood, G. G. Wildgoose, A. Crossley, R. M. J. Jacobs, J. H. Jones, R. G. Compton, Chem. Mater. 2007, 19, 4964-4974.

[51] P. T. Lee, J. C. Harfield, A. Crossley, B. S. Pilgrim, R. G. Compton, RSC Adv. 2013, 3, 7347-7354. 